\title{
Níveis de concentrado na dieta de bezerros
}

\section{Marinaldo Divino Ribeiro ${ }^{1^{*}}$, José Carlos Pereira ${ }^{2}$, Vitor Pereira Bettero ${ }^{1}$, Augusto César de Queiroz $^{2}$, Marcone Geraldo Costa ${ }^{1}$, Fernando de Paula Leonel ${ }^{1}$}

\footnotetext{
${ }^{1}$ Programa de Pós-graduação em Zootecnia da UFV.

2 Departamento de Zootecnia da UFV.
}

RESUMO - Objetivou-se avaliar níveis de concentrado para bezerros em crescimento. Foram utilizados quatro bezerros mestiços, Holandês $\times$ Zebu, com idade média de 7 meses e $155 \mathrm{~kg}$ de peso vivo, distribuídos em quadrado latino (4×4). Os animais foram alimentados à vontade, na forma de dieta completa contendo os níveis de 20, 40, 60 e 80\% de concentrado, com base na matéria seca (MS). As dietas foram compostas de feno de Cynodon dactylon, fubá de milho, farelo de soja e mistura mineral e foram isoprotéicas (15,4\%). Os consumos de MS, matéria orgânica (MO), fibra em detergente neutro (FDN) e carboidratos totais (CT) apresentaram comportamento linear e os consumos de proteína bruta (PB) e nutrientes digestíveis totais (NDT), comportamento quadrático, em kg/dia. Quando calculados em \%PV, os consumos de MO, PB, EE e NDT apresentaram comportamento quadrático, enquanto os de MS, FDN e CT tiveram comportamento linear. Os coeficientes de digestibilidade aparente total da MS e PB foram influenciados de forma quadrática pelos níveis de concentrado, enquanto os de MO, EE, FDN e CT tiveram comportamento linear. Não foi observado efeito dos níveis de concentrado sobre a concentração média de nitrogênio amoniacal em cada tempo de análise. Entretanto, para pH, observou-se influência dos níveis nos tempos analisados. Os níveis de concentrado não influenciaram a concentração média de glicose sérica, mas tiveram efeito linear negativo sobre o nitrogênio uréico sérico (NUS) em cada tempo pós-prandial. Pode-se incluir até $60 \%$ de concentrado na dieta de bezerros, entretanto níveis maiores podem comprometer a utilização do volumoso.

Palavras-chave: alimentação, consumo, digestibilidade

\section{Levels of concentrate in the diet of calves}

\begin{abstract}
The objective of this study was to evaluate the levels of concentrate for growing calves. Four Holstein $\times$ Brahman crossbred calves with average age of 7 months and $155 \mathrm{~kg}$ of body weight were used, distributed into one Latin square design $(4 \times 4)$. The animals were fed ad libtum in the form of complete diet containing levels of $20,40,60$ and $80 \%$ of concentrate on the dry matter basis (DM). The diets were composed of Cynodon dactylon hay, corn, soybean meal and mineral mixture, and were isoprotein (15.4\%). The DM, organic matter (OM), neutral detergent fiber (NDF) and total carbohydrate (TC) consumption showed linear response; and crude protein (CP) and total digestible nutrients (TDN), quadratic response; expressed in $\mathrm{kg} / \mathrm{day}$. When expressed in \%BW, the $\mathrm{OM}, \mathrm{CP}, \mathrm{EE}$ and TDN consumption presented quadratic behavior; as DM, NDF and TC showed linear behavior. The apparent total digestibility DM and CP coefficients were quadratic influenced by the levels of concentrate, while OM, EE, NDF and TC showed linear behavior. No effect was observed for the average concentration of ammoniac nitrogen, depending on the levels of concentrate, for each time of analysis. However, for $\mathrm{pH}$, there was influence of the levels for the times analyzed. Likewise, no effect was observed for the average concentration of serum glucose, however, for urea nitrogen serum (UNS), a linear negative effect was observed, depending on the levels for each post-feeding time. Therefore, up to $60 \%$ of concentrate could be included in the diet of calves; however higher levels can affect the use of bulky.
\end{abstract}

Key Words: consumption, digestibility, feeding

\section{Introdução}

O animal necessita ingerir quantidades adequadas de nutrientes para exercer suas funções fisiológicas e atender às exigências de mantença, crescimento e produção. Segundo Gomide \& Queiroz (1994), os alimentos podem ser classificados quanto aos seus valores nutritivo e alimentício. O valor nutritivo refere-se à composição bromatológica e à digestibilidade do alimento. Ullyatt (1973) define o valor alimentício como o potencial de ingestão de nutrientes que habilita o animal a realizar sua função produtiva. Assim, entende-se que o conceito de valor alimentício é mais amplo

Este artigo foi recebido em 5/12/2007 e aprovado em 8/9/2008. 
que o de valor nutritivo, pois inclui o conceito de consumo. Analogamente, como a composição e a digestibilidade são características inerentes ao alimento (Coelho da Silva, 2006), o consumo e sua intensidade são importantes nos sistemas de produção animal, pois determinam o nível de nutrientes ingeridos e a resposta animal (Van Soest, 1994).

Uma vez ingeridos, os alimentos passam pela digestão, um processo de conversão de macromoléculas do alimento em suas unidades construtivas ou em compostos simples que podem ser absorvidos no trato gastrintestinal. Medidas de digestibilidade contribuem para o desenvolvimento de sistemas e para a descrição e avaliação do potencial nutritivo dos alimentos (Van Soest, 1994). Todavia, muitos fatores influenciam a digestibilidade, como a composição dos alimentos e da ração, o preparo dos alimentos e os fatores relacionados ao animal e ao nível nutricional (Merchen, 1993).

Segundo Signoretti et al. (1999), uma das maneiras de se conseguir máximo consumo de energia, em ruminantes, é a manipulação da proporção de concentrado:volumoso. Mudando-se a proporção de volumoso da ração de 100 para $50 \%$, o consumo de matéria seca aumenta em torno de 35\% e melhora a digestibilidade total da ração, refletindo em maior digestibilidade do concentrado. Por outro lado, há considerável decréscimo da digestibilidade da fibra, em decorrência do menor tempo de permanência do volumoso no trato digestivo. Essas informações sugerem que os efeitos favoráveis da adição de concentrado na dieta apresentam comportamento curvilíneo e ponto ótimo que varia principalmente com a qualidade do volumoso (Mattos, 1993).

Com este trabalho objetivou-se avaliar os efeitos da inclusão de concentrado à dieta sobre o consumo, a digestão e as características ruminais e fisiológicas de bezerros em crescimento.

\section{Material e Métodos}

O experimento foi realizado na Unidade de Pesquisa, Ensino e Extensão em Gado de Leite do Departamento de Zootecnia da Universidade Federal de Viçosa, em Viçosa, Minas Gerais, no período de maio a setembro de 2006.

Foram utilizados quatro bezerros, não-castrados, com 7 meses de idade e $155 \mathrm{~kg}$ de peso corporal médio inicial, fistulados no rúmen. Os animais foram distribuídos em quadrado latino (4 dietas e 4 períodos de 16 dias) e mantidos com dietas com relações concentrado:volumoso de 20:80, 40:60, 60:40 e 80:20, com base na matéria seca.

As dietas experimentais (Tabelas 1 e 2 ) foram formuladas para ser isoprotéicas e promover ganho de peso de 0,8 kg/dia (NRC, 2001).
Tabela 1 - Composição das dietas experimentais (\% MS)

\begin{tabular}{|c|c|c|c|c|}
\hline \multirow[t]{2}{*}{ Ingrediente } & \multicolumn{4}{|c|}{$\begin{array}{c}\text { Nível de concentrado da } \\
\text { dieta (\% MS) }\end{array}$} \\
\hline & 20 & 40 & 60 & 80 \\
\hline Feno de coast-cross & 80,00 & 60,00 & 40,00 & 20,00 \\
\hline Milho & 0,00 & 20,45 & 40,90 & 61,35 \\
\hline Farelo de soja & 18,32 & 17,86 & 17,40 & 16,94 \\
\hline Mistura mineral $^{1}$ & 1,68 & 1,69 & 1,70 & 1,71 \\
\hline \multicolumn{5}{|l|}{ Composição nutricional } \\
\hline Matéria seca & 88,47 & 88,36 & 88,24 & 88,12 \\
\hline Matéria mineral & 7,73 & 6,78 & 5,83 & 4,88 \\
\hline Matéria orgânica & 91,87 & 92,87 & 93,86 & 94,85 \\
\hline Proteína bruta & 15,40 & 15,40 & 15,40 & 15,40 \\
\hline Extrato etéreo & 1,35 & 1,90 & 2,45 & 2,99 \\
\hline Fibra em detergente neutro & 66,72 & 53,03 & 39,33 & 25,63 \\
\hline Carboidratos totais & 75,51 & 75,92 & 76,32 & 76,73 \\
\hline
\end{tabular}

${ }^{1}$ Composição (\%): fosfato bicácalcico - 41,66; sal comum - 56,79; sulfato de cobre - 0,20; sulfato de zinco - 1,19; iodato de potássio - 0,03; sulfato de cobalto - 0,05; selenito de sódio - 0,08.

Tabela 2 - Composição nutricional do feno e dos concentrados (\%MS)

\begin{tabular}{lrrrrr}
\hline Nutriente $^{1}$ & \multirow{2}{*}{ Feno } & \multicolumn{4}{c}{$\begin{array}{c}\text { Nível de concentrado } \\
\text { da dieta (\% MS) }\end{array}$} \\
\cline { 2 - 6 } & & \multicolumn{1}{c}{20} & 40 & 60 & \multicolumn{1}{c}{80} \\
\hline Matéria seca & 92,30 & 89,43 & 89,23 & 89,34 & 89,10 \\
Matéria mineral & 10,24 & 16,18 & 7,94 & 8,72 & 7,17 \\
Matéria orgânica & 89,24 & 83,82 & 92,06 & 91,28 & 92,83 \\
Proteína bruta & 12,47 & 15,80 & 20,75 & 18,96 & 14,52 \\
Extrato etéreo & 1,82 & 0,50 & 1,82 & 1,85 & 1,37 \\
Fibra em detergente & 71,72 & 13,13 & 13,98 & 15,26 & 16,92 \\
neutro & & & & & \\
Carboidratos totais & 76,68 & 67,52 & 69,48 & 70,47 & 76,94 \\
\hline
\end{tabular}

Os animais foram alimentados uma vez ao dia, sempre pela manhã, na forma de dieta completa. Diariamente, foram pesados o alimento oferecido e as sobras para ajustar o consumo e garantir sobra de 5 a $10 \%$ da matéria natural. O consumo individual médio dos animais foi

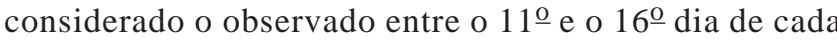
período experimental.

Durante o período de determinação do consumo individual médio, também foram coletadas amostras diárias do concentrado, do feno e das sobras.

O coeficiente de digestibilidade aparente total foi determinado pelo método indireto utilizando-se como indicador a fibra em detergente ácido indigestível (FDAi). As amostras de fezes, em quantidade aproximada de $200 \mathrm{~g}$, foram coletadas em intervalos de 26 horas, com início às $8 \mathrm{~h}$ do $12^{\mathrm{o}}$ dia e término às $16 \mathrm{~h}$ do $16^{0}$ o dia, totalizando cinco coletas.

As amostras de concentrado, feno, sobras e fezes foram secas em estufa com circulação forçada de ar, a $60 \pm 5^{\circ} \mathrm{C}$, por 72 horas (Silva \& Queiroz, 2002). Em seguida, foram 
moídas em peneira de $1 \mathrm{~mm}$ e armazenadas em forma de amostras compostas, com base no peso seco de cada subamostra, por animal e período, para posterior determinação da composição bromatológica e da concentração do indicador.

Na determinação do indicador, aproximadamente 1,0 g das amostras dos alimentos, das sobras e das fezes foi incubado em sacos de tecido-não-tecido (TNT - $100 \mathrm{~g} / \mathrm{m}^{2}$ ), obedecendo à relação de $20 \mathrm{mg}$ de $\mathrm{MS} / \mathrm{cm}^{2}$ de superfície (Nocek, 1988), no rúmen, ao final de todo o experimento, durante 144 horas, segundo adaptação da técnica descrita por Cochran et al. (1986). Após incubação, o material remanescente foi submetido à análise de fibra em detergente ácido para estimativa da digestibilidade dos nutrientes.

Nas amostras de alimentos, sobras e fezes, foram determinados os teores de matéria seca (MS), matéria orgânica (MO), matéria mineral (MM), extrato etéreo (EE) e proteína bruta (PB) (Silva \& Queiroz, 2002), fibra em detergente neutro (FDN) e fibra em detergente ácido indigestível (FDAi) (Van Soest et al., 1991). Os carboidratos totais (CT) e o consumo de nutrientes digestíveis totais (CNDT) foram estimados pela diferença entre o ingerido e o recuperado nas fezes de cada nutriente, com base na matéria seca, conforme as equações de Sniffen et al. (1992).

Os coeficientes de digestibilidade aparente total de MS, MO, EE, FDN e CT foram determinados conforme descrição de Coelho da Silva \& Leão (1979).

No $14^{\circ}$ dia de cada período experimental, amostras de líquido ruminal $(100 \mathrm{~mL})$ foram manualmente coletadas imediatamente antes e após 2, 4, 6 e 8 horas do fornecimento da alimentação. As leituras de $\mathrm{pH}$ foram feitas imediatamente após as coletas, utilizando-se peagâmetro digital. Para determinação da concentração de nitrogênio amoniacal ( $\mathrm{N}-\mathrm{NH}_{3}$ ), amostras de aproximadamente $50 \mathrm{~mL}$ de líquido ruminal foram filtradas em gaze e adicionadas em recipiente contendo $1 \mathrm{~mL}$ de ácido sulfúrico 1:1, que foram armazenados a $-10^{\circ} \mathrm{C}$ para análises posteriores do teor de $\mathrm{N}-\mathrm{NH}_{3}$. Após o descongelamento, foram retiradas alíquotas de $10 \mathrm{~mL}$, que foram acrescidas de $1 \mathrm{~mL}$ de ácido tricloroacético $10 \%$ e centrifugadas por 15 minutos a $5.000 \mathrm{rpm}$. Posteriormente, das amostras centrifugadas foram retiradas alíquotas de $2 \mathrm{~mL}$ do sobrenadante, as quais foram destiladas com solução de $\mathrm{KOH} 2 \mathrm{~N}$ (132 g de KOH/L de $\mathrm{H}_{2} \mathrm{O}$ destilada) e tituladas com ácido apropriado.

No 16 o dia de cada período experimental, foram tomadas amostras de sangue, de aproximadamente $10 \mathrm{~mL}$, antes e 4 horas após a alimentação, via jugular, em tubos vacutainers. As amostras foram centrifugadas a $2.500 \mathrm{rpm}$, por 15 minutos, e o soro armazenado a $-10^{\circ} \mathrm{C}$ em tubos tipo eppendorf para posteriores análises de glicose e nitrogênio uréico. As leituras das concentrações dos metabólitos foram feitas utilizando-se kits comerciais correspondentes.

O comportamento das médias foi interpretado por regressão e correlação linear (Myers, 1990). Todos os procedimentos de regressão não-linear aplicados para ajustamento dos dados aos modelos foram conduzidos segundo o algoritmo iterativo de Gauss-Newton (Souza, 1998). Os procedimentos estatísticos foram realizados pelo programa Statistical Analysis System (SAS, 2000) adotando-se 0,05 como nível crítico de probabilidade para o erro tipo I.

\section{Resultados e Discussão}

Os consumos médios de nutrientes, em quilograma por dia (kg/dia), foram influenciados pelos níveis de concentrado na dieta (Tabela 3). Os consumos médios de MS, MO, FDN e CT tiveram comportamento linear, enquanto os de PB, EE e NDT tiveram comportamento quadrático $(\mathrm{P}<0,05)$.

O aumento no consumo de MS com os níveis de concentrado provavelmente se deve à ingestão de FDN, que diminuiu conforme aumentaram os níveis de concentrado. Assim, é possível que o consumo tenha sido limitado pelos altos níveis de volumoso, como resultado do efeito de enchimento do rúmen, ocasionado pelo aumento dos níveis de fibra. O enchimento ruminal pode ser explicado pelo maior tempo de permanência da forragem na câmara fermentativa, uma vez que, estando as demais exigências para o crescimento microbiano supridas, a utilização da fibra demanda tempo para que os microrganismos celulolíticos reconheçam o substrato, colonizem as células e realizem a despolimerização da parede celular vegetal. Quanto maior o conteúdo de parede celular vegetal rico em lignina, menor a extensão de utilização dos carboidratos fibrosos e maior o tempo para que os resíduos não-digeríveis escapem dos compartimentos rúmen-retículo, reduzindo o consumo pelo animal, por indisponibilidade de espaço físico na câmara fermentativa. O mecanismo pelo qual a presença do alimento fibroso no rúmen-retículo regula o consumo está relacionado à emissão de sinais ao centro de controle da saciedade, localizado na medula oblonga, que são captados por mecanorreceptores e receptores de tensão, presentes na parte cranial do rúmen e no retículo (Coelho da Silva, 2006).

Comportamento dos consumos de MS e FDN semelhante ao observado neste trabalho foi relatado por Araújo et al. (1998), Ladeira et al. (1999), Tibo et al. (2000) e Dias et al. (2000). Todavia, Carvalho et al. (1997a), Bürger et al. (2000) e Ítavo et al. (2002) não encontraram efeito do aumento dos níveis de concentrado nas dietas sobre o consumo de MS. 
Tabela 3 - Consumos médios de nutrientes em bezerros alimentados com rações com diversos níveis de concentrado (NC)

\begin{tabular}{|c|c|c|c|c|c|c|c|c|}
\hline \multirow[t]{2}{*}{ Nutriente } & \multicolumn{4}{|c|}{ Nível de concentrado (\%MS) } & \multicolumn{2}{|c|}{ Valor de $\mathrm{P}$} & \multirow[t]{2}{*}{ CV (\%) } & \multirow[t]{2}{*}{ ER } \\
\hline & 20 & 40 & 60 & 80 & Linear & Quadrático & & \\
\hline \multicolumn{9}{|l|}{ Quilograma por dia (kg/dia) } \\
\hline Matéria seca & 4,64 & 4,98 & 5,66 & 5,29 & 0,0160 & 0,0912 & 6,91 & 6 \\
\hline Matéria orgânica & 4,09 & 4,51 & 5,13 & 4,88 & 0,0061 & 0,0851 & 6,93 & 7 \\
\hline Proteína bruta & 0,60 & 0,79 & 0,93 & 0,74 & 0,0043 & 0,0004 & 7,06 & 8 \\
\hline Extrato etéreo & 0,06 & 0,10 & 0,13 & 0,11 & $<0,0001$ & 0,0002 & 6,38 & 9 \\
\hline Fibra em detergente neutro & 2,74 & 2,33 & 2,06 & 1,39 & $<0,0001$ & 0,2253 & 9,21 & 10 \\
\hline Carboidratos totais & 3,48 & 3,67 & 4,14 & 4,08 & 0,0094 & 0,4003 & 6,97 & 11 \\
\hline Nutrientes digestíveis totais & 2,36 & 3,01 & 3,70 & 3,70 & $<0,0001$ & 0,0100 & 5,48 & 12 \\
\hline \multicolumn{9}{|c|}{ Porcentagem do peso vivo (\% PV) } \\
\hline Matéria seca & 2,35 & 2,45 & 2,86 & 2,63 & 0,0056 & 0,0520 & 5,24 & 13 \\
\hline Matéria orgânica & 2,07 & 2,22 & 2,59 & 2,43 & 0,0018 & 0,0465 & 5,24 & 14 \\
\hline Proteína bruta & 0,31 & 0,39 & 0,47 & 0,37 & 0,0008 & $<0,0001$ & 4,93 & 15 \\
\hline Extrato etéreo & 0,03 & 0,05 & 0,06 & 0,06 & $<0,0001$ & $<0,0001$ & 4,95 & 16 \\
\hline Fibra em detergente neutro & 1,39 & 1,15 & 1,04 & 0,69 & $<0,0001$ & 0,1958 & 7,36 & 17 \\
\hline Carboidratos totais & 1,76 & 1,81 & 2,09 & 2,03 & 0,0032 & 0,3764 & 5,35 & 18 \\
\hline Nutrientes digestíveis totais & 1,20 & 1,49 & 1,87 & 1,84 & $<0,0001$ & 0,0003 & 2,61 & 19 \\
\hline
\end{tabular}

* Significativo quando $\mathrm{P}<0,05$, pelo teste de $\mathrm{t} ; \mathrm{CV}=$ coeficiente de variação; $\mathrm{ER}=$ equação de regressão.

$6-\hat{\mathrm{Y}}=4,480180+0,013190 * N C, \mathrm{r}^{2}=0,61 ; 7-\hat{\mathrm{Y}}=3,906200+0,014890 * N C, \mathrm{r}^{2}=0,72 ; 8-\hat{\mathrm{Y}}=0,157430+0,026370 * \mathrm{NC}-0,000237 * N C^{2}, \mathrm{R}^{2}=0,94 ; 9-\hat{\mathrm{Y}}=0,060470$ $-0,001510 * N C+0,000094 * N C^{2}, R^{2}=0,98 ; 10-\hat{Y}=3,206080-0,021550 * N C, r^{2}=0,97 ; 11-\hat{Y}=3,279710+0,011270 * N C, r^{2}=0,85 ; 12-\hat{Y}=1,209360+0,063940 * N C$ - 0,000405*NC ${ }^{2}, R^{2}=0,96 ; 13-\hat{Y}=3,519680-0,106290 * N C, R^{2}=0,97 ; 14-\hat{Y}=2,934070-0,081040 * N C+0,002220 * N C^{2}, R^{2}=0,96 ; 15-\hat{Y}=0,390850-$ $0,011410 * N C+0,000430 * N C^{2}, R^{2}=0,96 ; 16 \hat{Y}=0,040980-0,001590 * N C+0,000066 * N C^{2}, R^{2}=0,97 ; 17-\hat{Y}=1,615380-0,10960 * N C, r^{2}=0,96 ; 18-\hat{Y}=2,546180$ $-0,069350 * N C, R^{2}=0,97 ; 19-\hat{Y}=1,489420-0,037660 * N C+0,00136 * N C^{2}, R^{2}=0,98$

Os níveis de concentrado na dieta tiveram efeito linear positivo sobre os consumos médios de matéria orgânica e carboidratos totais, o que pode ser explicado pelo maior consumo de MS quando os animais receberam rações com maiores quantidades de concentrado e pela maior concentração desses componentes nas dietas com os níveis mais elevados de concentrado (Tabela 1). Os resultados encontrados confirmam os reportados por Ladeira et al. (1999), que, trabalhando com níveis de concentrado de 25; 37,5; 50; 62,5 e $75 \%$ da MS para novilhos Nelores com peso vivo de 244,6 kg, encontraram valores de 4,58; 3,97; 4,97; 5,62; 5,06 para MO (\%) e 3,72; 3,26; 4,25; 5,05 e 4,30 para CT (\%) em função dos respectivos níveis de concentrado. Por outro lado, Carvalho et al. (1997a), trabalhando com níveis de 20; 32,5; 45; 57,5 e 70\% da MS para novilhos anelorados com peso vivo de $186 \mathrm{~kg}$, não encontraram diferenças significativas $(\mathrm{P}>0,01)$ nos consumos de $\mathrm{MO}$ e CT, cujas médias foram iguais a 1,70 e 1,42, respectivamente. Esses autores consideraram que a ausência de efeito entre os níveis de concentrado esteve relacionada à diminuição dos teores de carboidratos estruturais e ao aumento dos carboidratos não-estruturais nos mais altos níveis de concentrado.

Embora não fosse esperado, visto que as dietas foram formuladas para ser isoprotéicas, o consumo de PB foi influenciado $(\mathrm{P}<0,05)$ pelo nível de concentrado $(\mathrm{NC})$ na dieta, possivelmente em virtude da variação dos teores médios de $\mathrm{PB}$ dos alimentos utilizados. O consumo médio de PB foi superior ao recomendado pelo NRC (1989), de 0,58 kg/dia para bezerros de $150 \mathrm{~kg}$ de massa corporal. O consumo máximo de PB estimado (891,83 g/dia) ocorre quando o nível de concentrado é de 55,70\% na composição final da dieta. Carvalho et al. (1997a) não encontraram relação significativa entre os níveis de concentrado e o consumo de PB em novilhos anelorados com $186 \mathrm{~kg}$ de massa corporal e consumo médio de $460 \mathrm{~g} /$ dia. Ladeira et al. (1999), no entanto, observaram efeito linear positivo dos níveis crescentes de concentrado em dietas em novilhos Nelores de 246,6 kg de massa corporal. Comportamento similar ao observado neste trabalho para o consumo de PB foi encontrado por Araújo et al. (1998).

O consumo de NDT comportou-se de forma quadrática. Exceto no nível de $80 \%$ de volumoso na dieta, o consumo de NDT foi superior ao recomendado pelo NRC (2001), de 2,50 kg/dia, para bezerros de $150 \mathrm{~kg}$ de massa corporal e ganho diário de $800 \mathrm{~g} / \mathrm{dia}$. O aumento no consumo de NDT éreflexo do aumento dos consumos de $\mathrm{PB}, \mathrm{EE}$ e CT, provenientes de fontes com menores restrições à digestão e ao aproveitamento dos desses nutrientes ao longo do trato digestório.

Os consumos médios de MO, PB, EE e NDT apresentaram comportamento quadrático, enquanto os de MS, FDN e CT tiveram comportamento linear $(\mathrm{P}<0,05)$ quando expressos em \%PV (Tabela 3). 
O consumo médio total de MS foi de 2,57\%PV e as médias, de 2,35 e 2,45, nos níveis de 20 e $40 \%$ de concentrado na dieta, respectivamente. O menor consumo de MS, igualmente observado para consumo em $\mathrm{kg} / \mathrm{dia}$, é reflexo da relação linear negativa entre os consumos de FDN e a maior participação de concentrado na dieta. Quando fornecidas as dietas com 20 e $40 \%$ de concentrado, os valores médios de consumo de FDN foram de 1,39 e 1,15 (\%), respectivamente. Considerando que os animais eram bezerros em crescimento, para estes níveis de participação de concentrado, a limitação do consumo de MS pode ter sido mesmo influenciada pela fração fibrosa, especialmente aquela indigestível, das dietas utilizadas, pois, conforme aumentou a participação de concentrado, os animais aumentaram o consumo objetivando atender aos requerimentos de energia para crescimento e ganho.

Os valores de consumo, \%PV, de MS observados neste trabalho são superiores aos encontrados por Bürger et al. (2000), Dias et al. (2000) e Ítavo et al. (2002) em pesquisa para avaliação de níveis de concentrado para bezerros. Todavia, os consumos de FDN foram maiores que aqueles relatados por Dias et al. (2000) e Ítavo et al. (2002), mas menores que aqueles encontrados por Bürger et al. (2000). As diferenças entre os resultados deste estudo e os reportados na literatura podem estar relacionadas à qualidade da fonte volumosa utilizada, aos níveis de concentrado na dieta total e aos animais utilizados.

O efeito linear negativo dos níveis de concentrado na dieta sobre o consumo de FDN reforça a natureza peculiar desse componente do alimento e sua influência nos eventos digestivos e na passagem do alimento pelo rúmen-retículo. Assim, quanto maior sua participação no total de MS ingerida, maior o efeito sobre a regulação do consumo, em decorrência do enchimento ruminal.

O nível de $60 \%$ de concentrado na dieta promoveu os maiores valores de consumo de MS, MO, PB, CT e NDT em $\mathrm{kg} /$ dia e \%PV. Esse resultado, em comparação aos menores valores desses componentes na dieta com $80 \%$ de concentrado, reflete a possível limitação da utilização desses nutrientes por desordem digestiva, como acidose, em grau variado, contínua ou em determinados momentos, após a alimentação, proporcionada pelo concentrado, uma vez que dietas ricas em concentrado diminuem a ruminação e a produção de saliva com poder tamponante que chega ao rúmen, necessária para manter o ambiente ruminal adequado ao crescimento microbiano e aos eventos fermentativos. Nessas circunstâncias, quando ocorre rápida queda do pH ruminal, há o favorecimento de bactérias que fermentam os carboidratos prontamente digestíveis, como amido, acentuando a acidose e ocasionando menor consumo.

Os consumo médios de MS, MO, PB, CT e NDT, em $\mathrm{kg} /$ dia e $\% \mathrm{PV}$, quando fornecida a dieta com $40 \%$ de concentrado foram maiores e os de FDN, menores, que os obtidos com o nível de $20 \%$ de concentrado. Essa observação é importante, pois a dieta com $40 \%$ de concentrado tem maior quantidade de carboidratos prontamente digestíveis, disponíveis e utilizados para melhorar o crescimento microbiano, potencializar a utilização da fonte volumosa e aumentar o consumo sem aumentar significativamente o custo da alimentação.

Os coeficientes de digestibilidade aparente totais da MS e PB apresentaram comportamento quadrático, enquanto os de MO, EE, FDN e CT, comportamento linear para $\mathrm{P}<0,05$ (Tabela 4).

As digestibilidades máximas de MS e PB foram estimadas com 89,52 e 58,01\% de concentrado nas rações experimentais. A maior digestibilidade da MS observada com as dietas ricas em concentrado foi ocasionada pela maior quantidade de MO digestível e, provavelmente, de carboidratos nãofibrosos nessas dietas. O menor coeficiente de digestibilidade da PB da dieta contendo $20 \%$ de concentrado pode estar relacionado ao fato de boa parte da proteína da fonte

Tabela 4 - Digestibilidade aparente total dos nutrientes em bezerros alimentados com rações com diversos níveis de concentrado

\begin{tabular}{|c|c|c|c|c|c|c|c|c|}
\hline \multirow[t]{2}{*}{ Nutriente $^{1}$} & \multicolumn{4}{|c|}{ Nível de concentrado (\%MS) } & \multicolumn{2}{|c|}{ Valor de $\mathrm{P}^{3}$} & \multirow[t]{2}{*}{ CV (\%) } & \multirow[t]{2}{*}{ ER } \\
\hline & 20 & 40 & 60 & 80 & Linear & Quadrático & & \\
\hline Matéria seca & 52,81 & 62,74 & 67,90 & 71,61 & $<0,0001$ & 0,0486 & 3,95 & 6 \\
\hline Matéria orgânica & 55,37 & 64,43 & 68,96 & 72,62 & 0,0001 & 0,1030 & 4,30 & 7 \\
\hline Proteína bruta & 54,21 & 65,50 & 66,34 & 63,44 & 0,0356 & 0,0239 & 7,58 & 8 \\
\hline Extrato etéreo & 44,98 & 54,08 & 66,69 & 83,27 & 0,0005 & 0,4117 & 13,62 & 9 \\
\hline Fibra em detergente neutro & 52,56 & 48,71 & 49,57 & 31,54 & 0,0186 & 0,1541 & 19,07 & 10 \\
\hline Carboidratos totais & 57,13 & 65,01 & 70,08 & 74,69 & $<0,0001$ & 0,2611 & 3,96 & 11 \\
\hline
\end{tabular}

* Significativo quando $\mathrm{P}<0,05$, pelo teste $\mathrm{t} ; \mathrm{CV}$ = coeficiente de variação; $\mathrm{ER}$ = equação de regressão.

$6-\hat{\mathrm{Y}}=40,59761+0,69649 * N C-0,003898 * N C^{2}, \mathrm{R}^{2}=1 ; 7-\hat{\mathrm{Y}}=51,27932+0,28138 * N C, \mathrm{r}^{2}=0,95 ; 8-\hat{\mathrm{Y}}=37,49014+1,0302 * N C-0,00888 * N C^{2}, \mathrm{R}^{2}=0,98$ $9-\hat{\mathrm{Y}}=30,38374+0,63744 * \mathrm{NC}, \mathrm{r}^{2}=0,98 ; 10-\hat{\mathrm{Y}}=61,15139-0,31112 * N C, \mathrm{r}^{2}=0,71 ; 11-\hat{\mathrm{Y}}=52,28959+0,28875 * \mathrm{NC}, \mathrm{r}^{2}=0,98$ 
volumosa estar indisponível e, portanto, indigestível, por estar inserida na fração fibrosa não utilizada pelos microrganismos ruminais, uma vez que as dietas foram formuladas para serem isoprotéicas. Segundo Van Soest (1994) e Reis \& Silva (2006), durante o processo de confecção de feno, o aquecimento da forragem durante a secagem pode favorecer a reação de Maillard e acarretar polimerização da hemicelulose e de açúcares com o grupo amino dos aminoácidos, fazendo com que esses aminoácidos passem a fazer parte da fração indigestível da fibra. Esse processo reduz a digestibilidade da proteína da forrageira, fato que pode ter ocorrido neste trabalho.

A digestibilidade da FDN reduziu conforme aumentaram os níveis de concentrado na dieta, provavelmente em virtude da redução do $\mathrm{pH}$ do ambiente ruminal, o que limita o crescimento de bactérias celulolíticas, como descrito por Russell (2002).

A digestibilidade dos carboidratos totais apresentou comportamento linear $(\mathrm{P}<0,05)$ positivo de acordo com os níveis de concentrado, provavelmente pela maior participação e pela digestibilidade da matéria orgânica, cujo comportamento foi similar.

Vários autores observaram influência da inclusão de concentrado na dieta, seja positiva seja negativa, sobre a digestibilidade de MS, PB, FDN eCT, independentemente do comportamento da regressão (Carvalho et al., 1997a; Araújo et al., 1998; Ladeira et al., 1999; Signoretti et al., 1999; Dias et al., 2000; Bürger et al., 2000; Tibo et al., 2000; Ítavo et al., 2002).

Não foi observado efeito $(\mathrm{P}>0,05)$ dos níveis de concentrado sobre a concentração média de nitrogênio amoniacal nos tempos de análise (Tabela 5). Entretanto, os níveis de concentrado influenciaram $(\mathrm{P}<0,05)$ o $\mathrm{pH}$ nos tempos analisados (Tabela 5). A maior concentração de amônia estimada, independentemente do nível de concentrado, foi de 29,41 mg/dL 4 horas após a alimentação, o que sugere intensa atividade proteolítica da microbiota ruminal logo após a ingestão de alimentos ou a reciclagem da uréia via parede ruminal e saliva. Carvalho et al. (1997b) relataram que existe grande controvérsia sobre a concentração de $\mathrm{N}-\mathrm{NH}_{3}$ ruminal para o crescimento microbiano. Conforme descrito por Odle \& Schaefer (1987), os requerimentos de $\mathrm{N}-\mathrm{NH}_{3}$ são a concentração mínima necessária para manter a taxa máxima de crescimento bacteriana. Segundo Eardman et al. (1986), a concentração de $\mathrm{N}-\mathrm{NH}_{3}$ para máxima digestão não é constante, mas varia de acordo com a fermentabilidade da dieta. Schaefer et al. (1980) e Slyter et al. (1979) sugeriram que a concentração de $\mathrm{N}-\mathrm{NH}_{3}$ requerida para máximo crescimento e síntese de proteína microbiana por unidade de substrato fermentado é de 5 a $6 \mathrm{mg} \mathrm{N}-\mathrm{NH}_{3} / \mathrm{dL}$, enquanto Owens \& Bergen (1983) afirmaram que a concentração de $\mathrm{N}-\mathrm{NH}_{3}$ para a síntese de proteína microbiana máxima varia de 0,35 a $29 \mathrm{mg} \mathrm{N}-\mathrm{NH}_{3} / \mathrm{dL}$ de fluido ruminal. Os valores observados neste trabalho são superiores aos preditos por esses autores, porém dentro do intervalo descrito por Owens \& Bergen (1983). Considerando as concentrações médias de $\mathrm{N}-\mathrm{NH}_{3}$, pode-se aventar que provavelmente houve perda de proteína na forma de $\mathrm{N}-\mathrm{NH}_{3}$ e os microrganismos que usam amônia como fonte de nitrogênio para crescimento, especialmente os celulolíticos, não utilizaram toda a amônia para crescimento e desdobramento da parede

Tabela 5 - Concentrações médias de nitrogênio amoniacal ( $\left.\mathrm{N}-\mathrm{NH}_{3}, \mathrm{mg} / \mathrm{dL}\right)$ e pH no líquido ruminal após a alimentação em bezerros alimentados com rações com diversos níveis de concentrado

\begin{tabular}{|c|c|c|c|c|c|c|c|c|}
\hline \multirow[t]{2}{*}{ Tempo após a alimentação } & \multicolumn{4}{|c|}{ Nível de concentrado (\%MS) } & \multicolumn{2}{|c|}{ Valor de $\mathrm{P}^{3}$} & \multirow[t]{2}{*}{ CV (\%) } & \multirow[t]{2}{*}{ ER } \\
\hline & 20 & 40 & 60 & 80 & Linear & Quadrático & & \\
\hline \multicolumn{9}{|c|}{$\mathrm{N}-\mathrm{NH}_{3}(\mathrm{mg} / \mathrm{dL})$} \\
\hline 0 & 19,93 & 10,24 & 14,75 & 22,81 & 0,1370 & 0,2726 & 58,67 & 1 \\
\hline 2 & 24,20 & 28,97 & 21,86 & 23,94 & 0,6897 & 0,7604 & 34,04 & 2 \\
\hline 4 & 24,90 & 37,04 & 26,46 & 29,23 & 0,9239 & 0,4230 & 37,06 & 3 \\
\hline 6 & 24,90 & 28,71 & 26,20 & 13,36 & 0,1037 & 0,1029 & 37,19 & 4 \\
\hline 8 & 24,64 & 24,98 & 19,60 & 16,57 & 0,1391 & 0,6781 & 36,17 & \\
\hline \multicolumn{9}{|c|}{$\mathrm{pH}$} \\
\hline 0 & 6,78 & 6,97 & 6,75 & 6,68 & 0,0731 & 0,0483 & 1,58 & 6 \\
\hline 2 & 6,72 & 6,67 & 6,40 & 5,99 & 0,0103 & 0,2795 & 4,67 & 7 \\
\hline 4 & 6,49 & 6,27 & 5,82 & 5,46 & $<0,0001$ & 0,4424 & 2,78 & 8 \\
\hline 6 & 6,23 & 6,08 & 5,54 & 5,05 & 0,0002 & 0,1930 & 3,87 & 9 \\
\hline 8 & 6,32 & 6,13 & 5,58 & 5,07 & 0,0004 & 0,2691 & 4,73 & 10 \\
\hline
\end{tabular}

$\mathrm{CV}=$ coeficiente de variação; ER = equação de regressão.

$1-\hat{\mathrm{Y}}=0,18125 ; 2-\hat{\mathrm{Y}}=0,74544 ; 3-\hat{\mathrm{Y}}=0,40825 ; 4-\hat{\mathrm{Y}}=0,29238.5-\hat{\mathrm{Y}}=0,44894$.

$6-\hat{\mathrm{Y}}=6,5925+0,01396 * \mathrm{NC}-0,00017 * N C^{2}, \mathrm{R}^{2}=0,66 ; 7-\hat{\mathrm{Y}}=7,06625-0,01239 * \mathrm{NC}, \mathrm{r}^{2}=0,90 ; 8-\hat{\mathrm{Y}}=6,8975-0,01771 * \mathrm{NC}, \mathrm{r}^{2}=0,98 ;$ $9-\hat{\mathrm{Y}}==6,74625-0,0204 * \mathrm{NC}, \mathrm{r}^{2}=0,96 ; 10-\hat{\mathrm{Y}}=6,85-0,02146 * \mathrm{NC}, \mathrm{r}^{2}=0,96$. 
celular vegetal. De acordo com Russell (2002), a fermentação da proteína no rúmen pode, muitas vezes, produzir mais amônia que os microrganismos podem utilizar, ocasionando mais de $25 \%$ de perda de proteína na forma de $\mathrm{N}-\mathrm{NH}_{3}$.

$\mathrm{O} \mathrm{pH}$ ruminal reduziu conforme aumentaram os níveis de concentrado na dieta dos animais e teve comportamento quadrático no tempo zero e linear nos demais tempos, $(\mathrm{P}<0,05)$. A redução do $\mathrm{pH}$ provavelmente se deve ao maior conteúdo de carboidratos prontamente digestíveis das dietas com as maiores proporções de concentrado. Os menores valores de $\mathrm{pH}$ ocorreram próximo às 6 horas após a alimentação em todos os níveis de concentrado utilizados. Comportamento semelhante foi observado por Bürger et al. (2000), exceto no tempo zero hora após a alimentação, com valores próximos àqueles descritos por Rotger et al. (2006).

$\mathrm{O} \mathrm{pH}$ do fluido ruminal varia de 5,5 a 6,5 para dietas concentradas e de 6,2 a 7,0 para dietas constituídas exclusivamente de volumoso. O tempo após a alimentação no qual o pH é mais baixo é de 0,4 e 4 horas e reflete o balanço entre o acúmulo de ácidos orgânicos, o influxo de tampões por meio da saliva e a presença ou liberação de tampões ou bases do alimento (Owens \& Goetsch, 1993).

Segundo Ørskov (1986) e Russell (2002), o comportamento ingestivo influi na redução do $\mathrm{pH}$ ruminal. Quando animal ingere o alimento de forma rápida, como ocorre quando se utilizam dietas ricas em concentrado, verificam-se rápida taxa de fermentação e redução da secreção salivar para manutenção do pH entre 6 e 7, em decorrência da estrutura física da dieta, que não estimula suficientemente a motilidade ruminal e a ruminação. De acordo com Russell (2002), a eficiência de síntese de proteína microbiana pode diminuir significativamente quando o $\mathrm{pH}$ é menor que 6 . O resultado observado para o $\mathrm{pH}$, exceto no tempo zero, foi semelhante ao encontrado por Carvalho et al. (1997b) e Dias et al. (2000), que constataram redução linear do pH com o aumento de 25 a $75 \%$ nos níveis de concentrado da dieta de bovinos mestiços com predominância de sangue Nelore. Rotger et al. (2006), no entanto, não verificaram diferença no pH quando empregaram as relações volumoso:concentrado de 12:88 e 30:70.

Segundo Lana et al. (2000), dietas ricas em concentrado promovem redução na concentração de amônia, em razão do efeito do $\mathrm{pH}$ sobre a taxa de desaminação bacteriana. Esses autores observaram que a taxa de desaminação em animais alimentados com rações à base de forragem foi maior que naqueles alimentados com rações com $90 \%$ de concentrado e que o $\mathrm{pH}$ teve efeito negativo sobre as bactérias desses animais. Essa observação suporta os menores valores encontrados nesta pesquisa, uma vez que a produção de amônia reduziu conforme se acrescentou concentrado à dieta (Tabela 5). Além disso, bovinos alimentados com forragem e concentrado apresentam diferentes populações de bactérias produtoras de amônia.

Não foi observado efeito $(\mathrm{P}>0,05)$ dos níveis de concentrado sobre a concentração média de glicose sérica, entretanto, houve efeito linear negativo $(\mathrm{P}<0,05)$ sobre o nível sérico de nitrogênio uréico (NUS) em cada tempo pósprandial (Tabela 6).

A concentração média de glicose foi igual a $87,28 \mathrm{mg} / \mathrm{dL}$, valor próximo ao observado por Jorge et al. (2002), que avaliaram a substituição de milho por farinha de varredura para bezerros holandeses e não encontraram diferenças entre os níveis de substituição de 0 a $100 \%$ de farinha de varredura e observaram glicose média de $82,6 \mathrm{mg} / \mathrm{dL}$ nos bezerros com 164 dias de idade. Todavia, esses valores são superiores aos descritos por Nussio et al. (2003), que avaliaram o uso de milho floculado e monensina para bezerras de até 12 semanas de vida e observaram glicose média de $72,72 \mathrm{mg} / \mathrm{dL}$, independentemente do nível de milho floculado e monensina.

Segundo Quigley et al. (1991), espera-se redução dos níveis de glicose sérica com o avanço da idade, em razão

Tabela 6 - Concentrações médias de glicose e nitrogênio uréico sérico (NUS) 0 e 4 horas pós-alimentação em bezerros alimentados com rações com diversos níveis de concentrado

\begin{tabular}{|c|c|c|c|c|c|c|c|}
\hline Tempo após a alimentação & \multicolumn{4}{|c|}{ Nível de concentrado (\%MS) } & $\begin{array}{l}\text { Valor P } \\
\text { Linear }\end{array}$ & CV (\%) & ER \\
\hline \multicolumn{8}{|c|}{ Glicose (mg/dL) } \\
\hline 0 & 84,00 & 91,50 & 95,00 & 92,75 & 0,4376 & 17,62 & \\
\hline 4 & 76,50 & 79,75 & 90,00 & 88,75 & 0,4903 & 34,16 & \\
\hline \multicolumn{8}{|c|}{ NUS (mg/dL) } \\
\hline 4 & 22,60 & 19,57 & 15,61 & 13,39 & 0,0225 & 26,00 & 4 \\
\hline
\end{tabular}

$\mathrm{CV}=$ coeficiente de variação; ER = equação de regressão.

$1-\hat{\mathrm{Y}}=90,81 ; 2-\hat{\mathrm{Y}}=83,75.4 ; 3-\hat{\mathrm{Y}}=24,75625-0,16834 * \mathrm{NC}, \mathrm{r}^{2}=0,83 ; 4-\hat{\mathrm{Y}}=25,68825-0,15786 * \mathrm{NC}, \mathrm{r}^{2}=0$,99. * Significativo quando $\mathrm{P}<0,05$, pelo teste $\mathrm{t}$. 
da atividade fermentativa ruminal. Entretanto, esses autores relataram que, para animais de até 14 semanas de idade, os níveis de glicose podem ser maiores, em decorrência da adaptação fisiológica da mudança de pré-ruminante para ruminante. Como referência, Quigley et al. (1991) relataram o valor de $76 \mathrm{mg} / \mathrm{dL}$ e Wittwer (2000) descreveu o intervalo mínimo de 21 a $41 \mathrm{mg} / \mathrm{dL}$. Assim, os valores observados neste trabalho são superiores aos relatados como referência e podem estar relacionados à utilização dos carboidratos prontamente digestíveis, que constituíram os concentrados, resultando no atendimento dos níveis séricos, a partir do propionato, via gliconeogênese, ou resultado da regulação homeostática do animal, cujo mecanismo é altamente sensível aos níveis de glicose sérica.

O efeito decrescente dos níveis de concentrado na concentração de NUS, associado aos valores mais baixos de $\mathrm{pH}$, e os níveis elevados de $\mathrm{N}-\mathrm{NH}_{3}$ ruminal sugerem que a absorção de amônia na forma não-ionizada foi comprometida, elevando a reciclagem de uréia para o rúmen, via rúmen-retículo e saliva. O valor encontrado neste trabalho, de 28,35 \pm 10, $94 \mathrm{mg} / \mathrm{dL}$, foi inferior ao valor-referência descrito por Gregory et al. (2004), para a concentração sérica de NUS nas condições brasileiras, o que, segundo Wittwer (2000), pode representar o desbalanço da energia e a quantidade de proteína degradável no rúmen ingerida. No entanto, foi superior ao encontrado por Jorge et al. (2002), de 11,20 mg/dL, em bezerros com 164 dias de idade alimentados com rações com 0 a 100\% de farinha de varredura em substituição ao milho.

\section{Conclusões}

A inclusão de concentrado em níveis de até $60 \%$ na dieta de bezerros em crescimento estimula o consumo e a digestibilidade dos nutrientes. Entretanto, níveis mais elevados podem diminuir o aproveitamento do alimento volumoso por reduzirem o $\mathrm{pH}$ ruminal.

\section{Literatura Citada}

ARAÚJO, G.G.L.; SILVA, J.F.C.; VALADARES FILHO, S.C. et al. Consumo e digestibilidade total dos nutrientes de dietas contendo diferentes níveis de volumoso, em bezerros. Revista Brasileira de Zootecnia, v.27, n.2, p.345-354, 1998.

ARCURI, P.B.; LOPES, F.C.F.; CARNEIRO, J.C. Microbiologia do rúmen. In: BERCHIELLI, T.T.; PIRES A.V.; OLIVEIRA, S.G. (Eds.) Nutrição de ruminantes. Jaboticabal: Funep, 2006. p.111-150.

BÜRGER, P.J.; PEREIRA, J.C.; COELHO DA SILVA, J.F. et al. Consumo e digestibilidade aparente total e parcial em bezerros holandeses alimentados com dietas contendo diferentes níveis de concentrado. Revista Brasileira de Zootecnia, v.29, n.1, p.206-214, 2000.
CARVALHO, A.U.; VALADARES FILHO, S.C.; SILVA, J.F.C. et al. Níveis de concentrados em dietas de zebuínos. 1. Consumo e digestibilidade aparente. Revista Brasileira de Zootecnia, v.26, n.5, p.986-995, 1997a.

CARVALHO, A.U.; VALADARES FILHO, S.C.; SILVA, J.F.C. et al Níveis de concentrados em dietas de zebuínos. 4. Concentrações de ruminais de amônia e $\mathrm{pH}$, taxa de passagem da digesta ruminal e degradação in situ dos alimentos. Revista Brasileira de Zootecnia, v.26, n.5, p.1016-1024, 1997b.

COCHRAN, R.C.; ADAMS, D.C.; WALLACE, J.D. et al. Predicting digestibility diets with internal markers: evaluation four potential markers. Journal of Animal Science, v.63, n.11, p.1476-1483, 1986.

COELHO DA SILVA, J.F. Mecanismos reguladores de consumo. In: BERCHIELLI, T.T.; PIRES A.V.; OLIVEIRA, S.G. (Eds.) Nutrição de ruminantes. Jaboticabal: Funep, 2006. p.57-78.

COELHO DA SILVA, J.F.; LEÃO, M.I. Fundamentos da nutrição dos ruminantes. Piracicaba: Livroceres, 1979. 384p.

DIAS, H.L.C.; VALADARES FILHO, S.C.; COELHO DA SILVA, J.F. et al. Consumo e digestões totais e parciais em novilhos F1 Limousin $x$ Nelore alimentados com cinco níveis de concentrado. Revista Brasileira de Zootecnia, v.29, n.2, p.545-554, 2000.

EARDMAN, R.A.; PROCTOR, G.H.; VANDERSALL, J.H. Effect of rumen ammonia concentration on "in situ" rate and extent of digestion of feedstuffs. Journal of Dairy Science, v.69, n.9, p.2312-2320, 1986.

GOMIDE, J.A.; QUEIROZ, D.S. Valor alimentício das Brachiarias. In: SIMPÒSIO SOBRE MANEJO DA PASTAGEM, 11., 1994, Piracicaba. Anais... Piracicaba: Fundação de Estudos Agrários Luiz de Queiroz, 1994. p.223-248.

GREGORY, L.; BIRGEL JR., E.H.; D’ANGELINO, J.L. et al. Valores de referência dos teores séricos da uréia e creatinina em bovinos da raça Jersey criados no estado de São Paulo. Influência dos fatores etários, sexuais e da infecção pelo vírus da leucose dos bovinos. Arquivo do Instituto de Biologia, v.71, n.3, p.339-345, 2004

ÍTAVO, L.C.V.; VALADARES FILHO, S.C.; SILVA, F.F. et al. Consumo e digestibilidades aparentes totais e parciais de nutrientes em novilhos alimentados com dietas contendo vários níveis de concentrado. Revista Brasileira de Zootecnia, v.31, n.3, p.1543-1552, 2002. (supl.).

JORGE, J.R.V.; ZEOULA, L.M.; PRADO, I.N. et al. Substituição do milho pela farinha de varredura (Manihot esculenta, Crantz) na ração de bezerros Holandês. Desempenho e parâmetros sanguíneos. Revista Brasileira de Zootecnia, v.31, n.1, p.194-204, 2002.

LADEIRA, M.M.; VALADARES FILHO, S.C.; SILVA, J.F.C. et al. Consumo e digestibilidades totais e parciais de dietas contendo diferentes níveis de concentrado, em novilhos nelore. Revista Brasileira de Zootecnia, v.28, n.2, p.395-403, 1999.

LANA, R.P.; CUNHA, L.C.; BORGES, A.C. Efeito da acidez no controle da produção de amônia e crescimento microbiano. Revista Brasileira de Zootecnia, v.29, n.6, p.1876-1882, 2000.

MATTOS, W.R.S. Nutrição para performance máxima. In: PEIXOTO, A.M. (Ed.) Nutrição de bovinos: conceitos básicos e aplicados. Piracicaba: Fundação de Estudos Agrários Luiz de Queiroz, 1993. p.209-222.

MERCHEN, N.R. Digestion, absorcion y excrecion en los ruminates. In: CHURCH, D.C. (Ed.) El rumiante: fisiología digestiva y nutrición. Zaragoza: Acríbia, 1993. p.191-223.

MYERS, R.H. Classical and modern regression with applications. Boston: PWS-Kent Publishing Co, 1990. 488p.

NATIONAL RESEARCH COUNCIL - NRC. Nutrient of requirements of dairy cattle. 7.ed. Washington, D.C.: National Academic Press, 2001. 362p.

NATIONAL RESEARCH COUNCIL - NRC. Nutrient of requirements of dairy cattle. 6.ed. Washington, D.C.: National Academic Press, 1989. 90p. 
NOCEK, J.E. In situ and other methods to estimate ruminal protein and energy digestibility: a review. Journal of Dairy Science, v.71, p.2051-2069, 1988.

NUSSIO, C.M.B.; SANTOS, F.A.P.; ZOPOLLATTO, M. et al. Processamento de milho (floculado vs. laminado a vapor) e adição de monensina para bezerras leiteiras, pré e pós desmama precoce. Revista Brasileira de Zootecnia, v.32, n.1, p.229-239, 2003.

ODLE, J.E.; SCHAEFER, D.M. Influence of rumen ammonia concentration on the rumen degradation rates of barley and maize. Bristh Journal of Nutrition, v.57, n.1, p.127-138, 1987.

ØRSKOV, E.R. Starch digestion and utilization in ruminants, Journal of Animal Science, v.63, n.5, p.1624-1633, 1986.

OWENS, F.N.; BERGEN, W.G. Nitrogen metabolism of ruminant animals: historical perspective, current understanding and future implications. Journal of Animal Science, v.57, suppl.2, p.498-518, 1983.

OWENS, F.N.; GOETSCH, A.L. Fermentación ruminal. In: CHURCH, D.C. (Ed.) El rumiante: fisiología digestiva y nutrición. Zaragoza: Acríbia, 1993. p.159-189.

QUIGLEY, J.D.; CALDWELL, L.A.; SINKS, D.D. et al. Changes in blood glucose, nonesterified fatty acids, and ketones in response to weaning and feed intake in young calves. Journal of Dairy Science, v.74, n.1, p.250-257. 1991.

REIS, R.A.; SILVA, S.C. Consumo de forragens. In: BERCHIELLI, T.T.; PIRES A.V.; OLIVEIRA, S.G. (Eds.) Nutrição de ruminantes. Jaboticabal: Funep, 2006. p.79-109.

RUSSELL, J.B. Rumen microbiology and its role in ruminant nutrition. Ithaca: Cornell University Press, 2002. 119p.

ROTGER, A.; FERRET, A.; CASALMIGLIA, S. et al. In situ degradability of seven protein plant supplements in heifers fed high concentrate diets with different forage to concentrate ratio. Animal Feed Science and Technology, v.125, n.1, p.73-87, 2006.

SCHAEFER, D.M.; DAVIS, C.L.; BRYANT, M.P. Ammonia saturation constants for predominant species of rumen bacteria. Journal of Dairy Science, v.63, n.8, p.1263, 1980.
SIGNORETTI, R.D.; SILVA, J.F.C.; FILHO, S.C.V. et al. Consumo e digestibilidade aparente em bezerros da raça Holandesa alimentados com dietas contendo diferentes níveis de volumoso. Revista Brasileira de Zootecnia, v.28, n.1, p.169-177, 1999.

SILVA, D.J.; QUEIROZ, A.C. Análise de alimentos: métodos químicos e biológicos. 3.ed. Viçosa: Editora UFV, 2002. 235p.

SLYTER, L.L.; SATTER, L.D.; DINIUS, D.A. Effect of ruminal ammonia concentration on nitrogen utilization by steers. Journal of Animal Science, v.48, p.906-912, 1979.

SNIFFEN, C.J.; O'CONNOR, J.D.; Van SOEST, P.J. et al. A net carbohydrate and protein system for evaluation cattle diets: II. Carbohydrate and protein availability. Journal of Animal Science, v.70, n.11, p.3562-3577, 1992.

SOUZA, G.S. Introdução aos modelos de regressão linear e não-linear. Brasília: EMBRAPA-SPI, 1998. 505p.

STATISTICAL ANALYSIS SYSTEMS - SAS. Statistical analysis system user's guide: basics. 7.ed. Cary: 2000. (CD-ROM).

TIBO, G.C.; VALADARES FILHO, S.C.; VALADARES, R.D. et al. Níveis de concentrado em dietas de novilhos mestiços F1 Simental x Nelore. I. Consumo e digestibilidade. Revista Brasileira de Zootecnia, v.29, n.3, p.910-920, 2000.

ULYATT, M.J. The feeding value of herbage. In: BUTLER, G.W.; BAILEY, R.W. (Eds.) Chemistry and biochemistry of herbage. London: Academic Press, 1973. v.3, p.131-178.

Van SOEST, P.J. Nutritional ecology of the ruminant. 2.ed. Ithaca: Cornell University Press, 1994. 476p.

Van SOEST, P.J.; ROBERTSON, J.B.; LEWIS, B.A. et al. Methods for dietary fiber, neutral detergent fiber, and nonstarch polyssacharides in relation to animal nutrition. Journal of Dairy Science, v.74, n.10, p.3583-3597, 1991.

WITTWER, F. Diagnóstico dos desequilíbrios metabólicos de energia em rebanhos bovinos. In: GONZÁLEZ, F.H.D.; BARCEllos, J.; PATINO, H.O.; RIBEIRO, L.A. (Eds.) Perfil metabólico em ruminantes: seu uso em nutrição e doenças nutricionais. Porto Alegre: UFRGS, 2000. p.9-22. 